\title{
Rapid forecasting of tsunami runup heights from 2-D numerical simulations
}

\author{
B. H. Choi ${ }^{1}$, V. Kaistrenko ${ }^{2}$, K. O. Kim ${ }^{3}$, B. I. Min ${ }^{1}$, and E. Pelinovsky ${ }^{4}$ \\ ${ }^{1}$ Department of Civil and Environmental Engineering, Sungkyunkwan University, Suwon, Korea \\ ${ }^{2}$ Tsunami Laboratory, Institute of Marine Geology and Geophysics, Yuzhno-Sakhalinsk, Russia \\ ${ }^{3}$ Korea Ocean Research \& Development Institute, Ansan, Korea \\ ${ }^{4}$ Department of Nonlinear Geophysical Processes, Institute of Applied Physics, Russian Academy of Sciences, \\ 46 Uljanov Street, 603950, Nizhny Novgorod, Russia
}

Received: 23 August 2010 - Revised: 5 January 2011 - Accepted: 24 January 2011 - Published: 8 March 2011

\begin{abstract}
We propose a method to compute tsunami runup heights that is based on an integration of numerical, 2-D shallow-water modelling and an analytical, 1-D long-wave runup theory. This approach provides a faster forecast of tsunami runup heights than a complicated coastal inundation model. Through simulations of potential tsunami scenarios, this approach can also be applied to long-term tsunami prediction. We tested the model by simulating the historical event in the East (Japan) Sea and found that the estimates of runup heights agreed well with the available observations.
\end{abstract}

\section{Introduction}

Numerical modeling of the propagation of tsunami waves is an important tool for forecasting tsunami heights and the risks posed to coastal populations. Previous analyses of tsunami characteristics have used the shallow-water model with a no-flux boundary condition at a depth of 5-10 $\mathrm{m}$ on the shore (Titov and Synolakis, 1998; Sato et al., 2003; Choi et al., 2003; Ioualalen et al., 2007; Schuiling et al., 2007; Zaitsev et al., 2009; Beisel et al., 2009). In this model, runup heights are determined using simplified formulae of the 1-D, analytic theory of long-wave runup for a fixed shape of an incident wave, whether a sine wave or a solitary wave (Choi et al., 2002a; Ward and Asphaug, 2003). The runup stage is included in the numerical model by taking into account the various assumptions concerning the hydraulic properties (roughness) of the dry land, an important calculation for tsunami risk assessment (Glimsdal et al., 2006; Lovholt et

Correspondence to: E. Pelinovsky (pelinovsky@hydro.appl.sci-nnov.ru) al., 2006; Dominey-Howes and Papathoma, 2007; Gonzalez et al., 2009; Dall'Osso et al., 2010; Gayer et al., 2010). The direct calculation of the propagation of the tsunami wave from its source to the coastal zone using a single numerical model results in low accuracy. As a partial solution, various nested methods with different mesh resolutions in the open sea and the coastal zone have been developed (Titov and Synolakis, 1995, 1998; Choi et al., 2003; Wei et al., 2008; Roger and Hebert, 2008; Roger et al., 2010; Titov et al., 2011). Near the coast, accurate computing of tsunami wave dynamics requires small grid steps of $10-100 \mathrm{~m}$. As a result, such numerical models are difficult to use in operational practice. For instance, in the East (Japan) Sea, tsunamis usually arrive at the eastern Korean coasts within 100 min. Thus, the runup height in coastal zones must be predicted well in advance, and it is for this reason that the Korea Meteorological Administration (KMA) uses the vertical wall approximation in its model of wave propagation. The model permits rapid warning, but it also yields low accuracy in its estimates of tsunami runup height.

In practice, the formula describing the runup of sine and solitary waves on a planar beach is used to approximate the tsunami runup heights; see, for instance, Choi et al. (2002a) and Ward and Asphaug (2003). It has been shown recently that the formulae for wave runup with various shapes can be parameterised and unified for incident waves of various shapes if the characteristic wavelength of the incident wave is determined on the level $2 / 3$ from maximal wave height (Didenkulova and Pelinovsky, 2008; Didenkulova, 2009). Defining the incident wave near the coast, where the bottom profile can be approximated by a planar beach, is not straightforward if the computation is performed in a domain with a non-reflected boundary condition. 
The primary purpose of this study is to develop a model that combines numerical simulations for wave dynamics far from the coast with analytical solutions for the wave runup. The novelty of our approach, as contrasted to previous studies (Choi et al., 2002a; Ward and Asphaug, 2003), lies in its original expression for the runup ratio. This new approach facilitates the rapid prediction of a tsunami's characteristics upon its arrival at the coast to help prevent tsunami-related disasters. Section 2 describes an analytical approach to compute the runup height using the wave height at the wall; this approach is based on a rigorous solution of a set of 1D shallow-water equations for waves above a planar beach. Section 3 presents a shallow-water numerical model for simulating tsunami propagation in the East (Japan) Sea. The combined model is tested in Sect. 4, which describes a numerical simulation of the 1993 event and calculations of the expected runup heights. Estimations of the runup heights along the Eastern Korean Coast are in close agreement with observations.

\section{Analytical approach to compute the runup height through the height of a tsunami wave at the wall}

In the analytical theory of long-wave runup, rigorous solutions of 1-D, nonlinear, shallow-water equations can be obtained for a planar beach using the Carrier - Greenspan transformation (Carrier and Greenspan, 1958) for the various shapes of the incident wave (Pedersen and Gjevik, 1983; Synolakis, 1987; Kaistrenko et al., 1991; Synolakis, 1991; Pelinovsky and Mazova, 1992; Tadepalli and Synolakis, 1994; Carrier et al., 2003; Kânoğlu, 2004; Tinti and Tonini, 2005; Kânoğlu and Synolakis, 2006; Didenkulova et al., 2006, 2008; Antuono and Brocchini, 2007, 2008, 2010; Didenkulova and Pelinovsky, 2008; Madsen and Fuhrman, 2008, Didenkulova, 2009; Briganti and Dodd, 2009; Dobrokhotov and Tirozzi, 2010). The important result here is that the linear and nonlinear theories predict the same maximal values for the runup height if the incident wave is determined far from the shore, and for this reason, linear theory can be applied to analyse the runup process. Within the framework of linear theory, rigorous solutions can be found for various bottom profiles, not only the planar beach. A popular approximation of the bottom profile is a planar beach combined with a flat bottom (a configuration usually applied in laboratory modeling). In this case, the incident and reflected waves are easily separated on the flat bottom, and the runup height of the monochromatic wave is (Shuto, 1972)

$$
R / A=\frac{2}{\sqrt{J_{0}^{2}(2 k L)+J_{1}^{2}(2 k L)}},
$$

where $R$ is the maximal runup height, $A$ is the amplitude of the incident wave, $L$ is the shelf width, $k$ is the wave number of the incident wave, and $J_{0}$ and $J_{1}$ are Bessel's functions. Using Fourier transformations, similar formulae (at

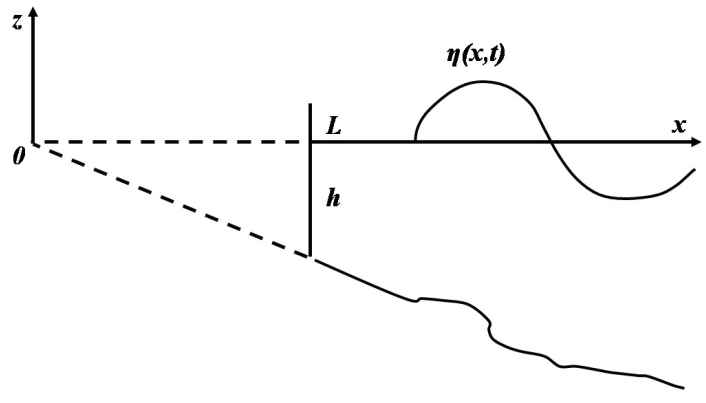

Fig. 1. Schematic presentation of the coastal zone

least in integral form) can be derived for an incident wave of arbitrary shape (Synolakis, 1987; Pelinovsky and Mazova, 1992). The amplification factor (1) has been used to estimate the runup heights observed on the Korean Coast during the 1993 tsunami (Choi et al., 2002a).

When applied to tsunamis, the bottom profile varies in the coastal zone and cannot be represented as flat. A classic numerical model includes the wall at depth $h$ and distance $L$ from the shore (Fig. 1). Numerical simulation can then capture the resulting oscillation of water level, $\eta(L, t)$. Selecting the incident and reflected waves from the wave records near the wall is not simple; here, we apply another approach based on rigorous solutions of the wave equation.

The shallow-water equations in the linear approximation can be reduced to the wave equation for the water displacement,

$\frac{\partial^{2} \eta}{\partial t^{2}}=\frac{\partial}{\partial x}\left[g h(x) \frac{\partial \eta}{\partial x}\right]$

where $g$ is the acceleration due to gravity, and $h(x)$ describes the bottom profile. The general solution of Eq. (2) can be found using the Fourier transformation

$\eta(x, t)=\frac{1}{2 \pi} \int_{-\infty}^{\infty} \tilde{\eta}(x, \omega) \cdot e^{-i \omega t} d \omega$

The Fourier transform $\tilde{\eta}(x, \omega)$ is the solution of the ordinary differential equation following from Eq. (2),

$\frac{d}{d x}\left[\operatorname{gh}(x) \frac{d \tilde{\eta}}{d x}\right]+\omega^{2} \tilde{\eta}=0$.

We assume that $h(x)=\alpha x$ everywhere and $\alpha$ is constant. For this case, an elementary solution of (4) is presented through the Hankel functions

$$
\begin{aligned}
& \tilde{\eta}(x, \omega)=B(\omega) \cdot H_{0}^{(1)}(\zeta)+A(\omega) \cdot H_{0}^{(2)}(\zeta) \\
& \zeta=2 \omega \sqrt{x / g \alpha}
\end{aligned}
$$

Using the asymptote of the zero-order terms of the Hankel function, it can be shown easily that Eq. (5) corresponds 
to the incident wave with amplitude $A$ (propagated onshore), and the first corresponds to the reflected wave with amplitude $B$ (propagated offshore). We assume that characteristics of the incident wave are known, and therefore, $A(\omega)$ can be found from the Fourier presentation of the incident wave.

We first analyse the wave runup on the vertical wall (Fig. 1). The boundary condition on the wall is

$$
\left.\frac{d \tilde{\eta}}{d x}\right|_{x=L}=0
$$

which leads to

$B(\omega) \cdot H_{1}^{(1)}(\omega T)+A(\omega) \cdot H_{1}^{(2)}(\omega T)=0$,

where $T$ is the travel time of the wave from the wall on depth $h$ to the shore,

$T=\frac{2 L}{\sqrt{g h}}=2 \sqrt{\frac{L}{g \alpha}}$.

Equation (5) for $x=L$ and (7) can serve as a system of equations to find the amplitudes of the incident and reflected waves,

$$
\begin{gathered}
A(\omega)=-\frac{\tilde{\eta}(L, \omega) H_{1}^{(1)}(\omega T)}{H_{0}^{(1)}(\omega T) H_{1}^{(2)}(\omega T)-H_{1}^{(1)}(\omega T) H_{0}^{(2)}(\omega T)}, \\
B(\omega)=\frac{\tilde{\eta}(L, \omega) H_{1}^{(2)}(\omega T)}{H_{0}^{(1)}(\omega T) H_{1}^{(2)}(\omega T)-H_{1}^{(1)}(\omega T) H_{0}^{(2)}(\omega T)} .
\end{gathered}
$$

It is easy to simplify these equations, taking into account that the denominator is the Wronskian of the Hankel functions [see Eq. (9.1.17) in Abramowitz and Stegun (1964)]:

$$
\begin{aligned}
A(\omega) & =\frac{i \pi \omega T H_{1}^{(1)}(\omega T)}{4} \tilde{\eta}(L, \omega), \\
B(\omega) & =-\frac{i \pi \omega T H_{1}^{(2)}(\omega T)}{4} \tilde{\eta}(L, \omega)
\end{aligned}
$$

Thus, the equations (10) can be used to compute the spectral amplitudes of the incident and reflected waves through the Fourier spectrum of the water oscillations on the wall.

We now consider the wave runup on the same planar beach with no vertical wall, assuming that the incident monochromatic wave has the same amplitude $A(\omega)$ as before. In this case, the bounded (on the shore) solution to (5) is

$\tilde{\eta}(x, \omega)=2 \cdot A(\omega) \cdot J_{0}(\zeta)$.

Using (11) and (9) to eliminate $A(\omega)$, we can calculate the wave field on a planar beach compared to the wave oscillation on the wall. In particular, the spectral amplitude of the water oscillations on the shore is

$\tilde{\eta}(0, \omega)=\frac{i \pi \omega T H_{1}^{(1)}(\omega T)}{2} \tilde{\eta}(L, \omega)$.

The expression (12) can be considered the runup ratio for a sine wave, which is discussed in Harbitz and Pedersen (1992) and Kaistrenko et al. (1999) on a planar beach. Using the Fourier transformation of (12), we can compute $\eta(0, t)$ through $\eta(L, t)$. The inverse Fourier transformation in this asymptotic case is expressed by the simple integral

$\eta(x=0, t)=\int_{0}^{t-T} \frac{t-\tau}{\sqrt{(t-\tau)^{2}-T^{2}}} \frac{d \eta(x=L, \tau)}{d \tau} d \tau$.

Equation (13) can be integrated by parts and written as

$\eta(x=0, t)=\int_{0}^{t-T} \sqrt{(t-\tau)^{2}-T^{2}} \cdot \frac{d^{2} \eta(x=L, \tau)}{d \tau^{2}} d \tau$.

In Eqs. (13) and (14), $t=0$ corresponds to the wave approaching the vertical wall. In the initial moment, it is assumed that $\eta(x=L, t=0)=d \eta(x=L, t=0) / d t=0$. The input function $\eta(x=L, t)$ gives the water wall oscillations computed from the 2-D model. The maximum of $\eta(x=0, t)$ in linear theory gives the maximal runup height of tsunami waves on the coast in nonlinear theory.

Thus, considering the two geometries of a nearshore planar beach (in the runup study) and a planar beach with a vertical wall at a fixed depth (the equivalent boundary condition), we have shown that the runup height can be expressed through the characteristics of the water oscillations on the vertical wall. This procedure is rapid and easily realised on computers. As a result, the numerical simulation of tsunami waves can be used for estimations of the runup heights of tsunami waves.

Several limitations of the proposed approach should be mentioned. First, the 1-D analytical runup theory is applied, whereas the numerical simulation of tsunami waves in real basins assumes 2-D geometry. This distinction means that 2-D effects (refraction, focusing, etc.) nearshore are not included in the model. The wave field on the wall generally contains the approaching waves propagated onshore and the trapped waves propagated alongshore. It is evident that the first waves in the time series near the wall are "onshore" waves (trapped waves approach later), and thus the interval of integration in Eqs. (13) or (14) should be bounded by the few first waves. The second limitation concerns the use of the approximation of the nearshore bottom profile and the vertical wall as a planar beach with the same slope. Real bathymetry near the wall can be approximated by the piecewise linear function (Kânoğlu and Synolakis, 1998) or by a power function (Didenkulova et al, 2009; Didenkulova and Pelinovsky, 2010). It is evident that near-shore bathymetric features influence the runup process and may affect the results described above. Another limitation is the ignoring of breaking effects in tsunami waves. Finally, the Eqs. (13) or (14) contain linear approximation. However, as noted earlier, the maximal runup height computed by linear and nonlinear theories is the same, suggesting that this last limitation is less important. The appropriateness of these assumptions can be 


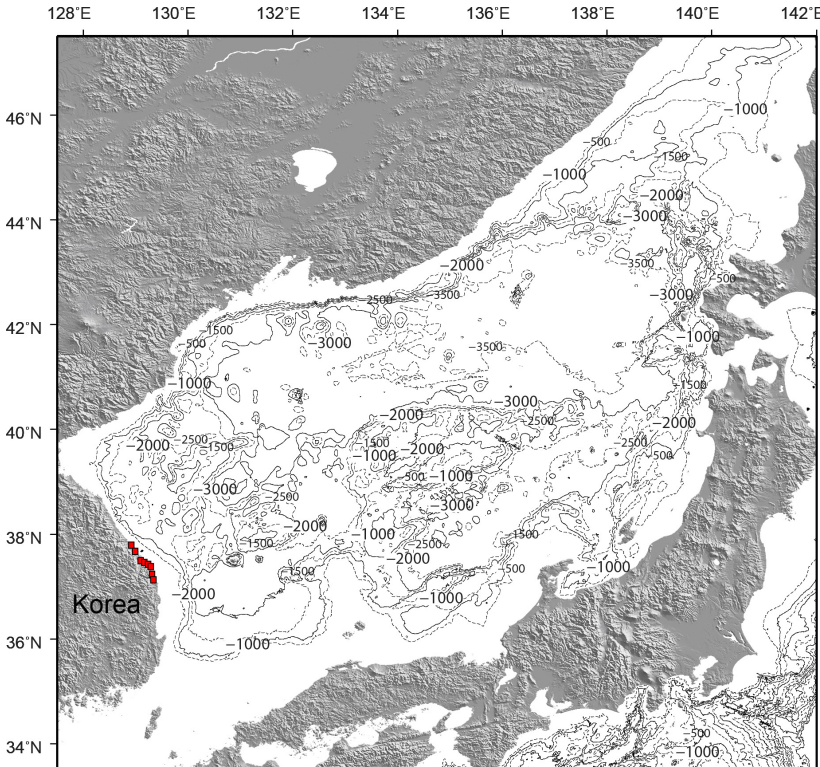

Fig. 2. Topography and bathymetry (contour unit: metre) of the East (Japan) Sea. The 8 dots along the Korean coast indicate beaches where comparisons between the observed and calculated runup heights were made (see Fig. 6).

tested through modeling historic events. In the next section the developed analytical approach that will be used in estimations of the 1993 tsunami runup heights in the East (Japan) Sea. A general description of this event is given in (Choi et al., 1994, 2003).

\section{Numerical model}

A finite-difference model (Choi et al., 2003) was developed to simulate the generation and propagation of the tsunami. The numerical model uses the linear shallow-water equation with a spherical coordinate system covering the East Sea area with mesh dimensions $959 \times 1118$, a mesh size of 1 angular min, and a 2-s time step (Fig. 2). The basic equations are

$\frac{\partial \eta}{\partial t}+\frac{1}{R \cos \phi}\left[\frac{\partial P}{\partial \chi}+\frac{\partial}{\partial \phi}(Q \cos \phi)\right]=0$,

$\frac{\partial P}{\partial t}+\frac{g h}{R \cos \phi} \frac{\partial \eta}{\partial \chi}-f Q=0$,

$\frac{\partial Q}{\partial t}+\frac{g h}{R} \frac{\partial \eta}{\partial \phi}-f P=0$.

In the equations above, $\phi$ and $\chi$ are latitude and longitude, $P$ and $Q$ are discharge per unit width in the direction of $\phi$ and $\chi$, respectively, $R$ is the radius of the earth, and $f$ is the Coriolis parameter.

We compiled all of the available topographic data with a digitisation of hydrographic charts, including Chinese and

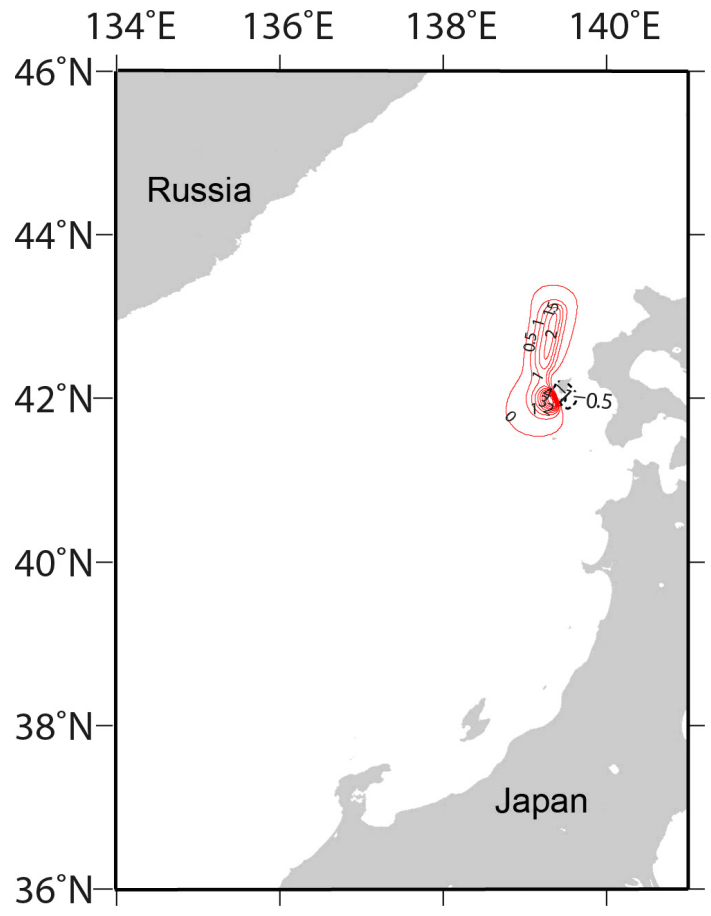

Fig. 3. The location and initial water elevations of the 1993 event. Solid and dashed lines indicate the positive and negative values, respectively. The contour interval is $0.5 \mathrm{~m}$.

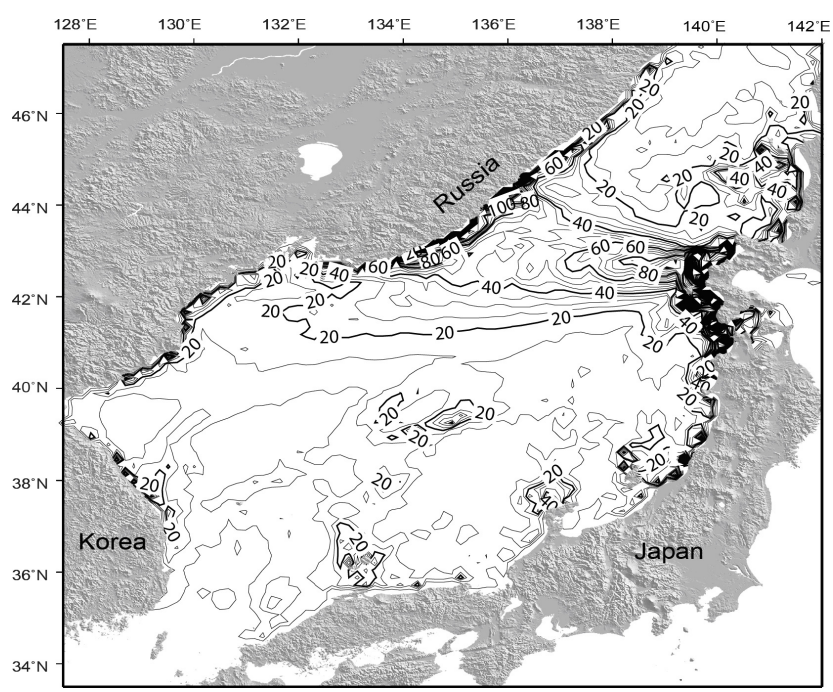

Fig. 4. The distribution of maximum wave heights $(\mathrm{cm})$ in the East (Japan) Sea for the 1993 tsunami.

Russian navigation charts and Korean hydrographic charts. These data were used to produce a 1-min gridded topography and bathymetry dataset for the region $\left(117^{\circ} \mathrm{E}\right.$ to $143^{\circ} \mathrm{E}$ longitude and $24^{\circ} \mathrm{N}$ to $52^{\circ} \mathrm{N}$ latitudes) (Fig. 2) with a refined 1 arc-second topography and bathymetry west of $135^{\circ}$ East longitude (Choi et al., 2002b). 

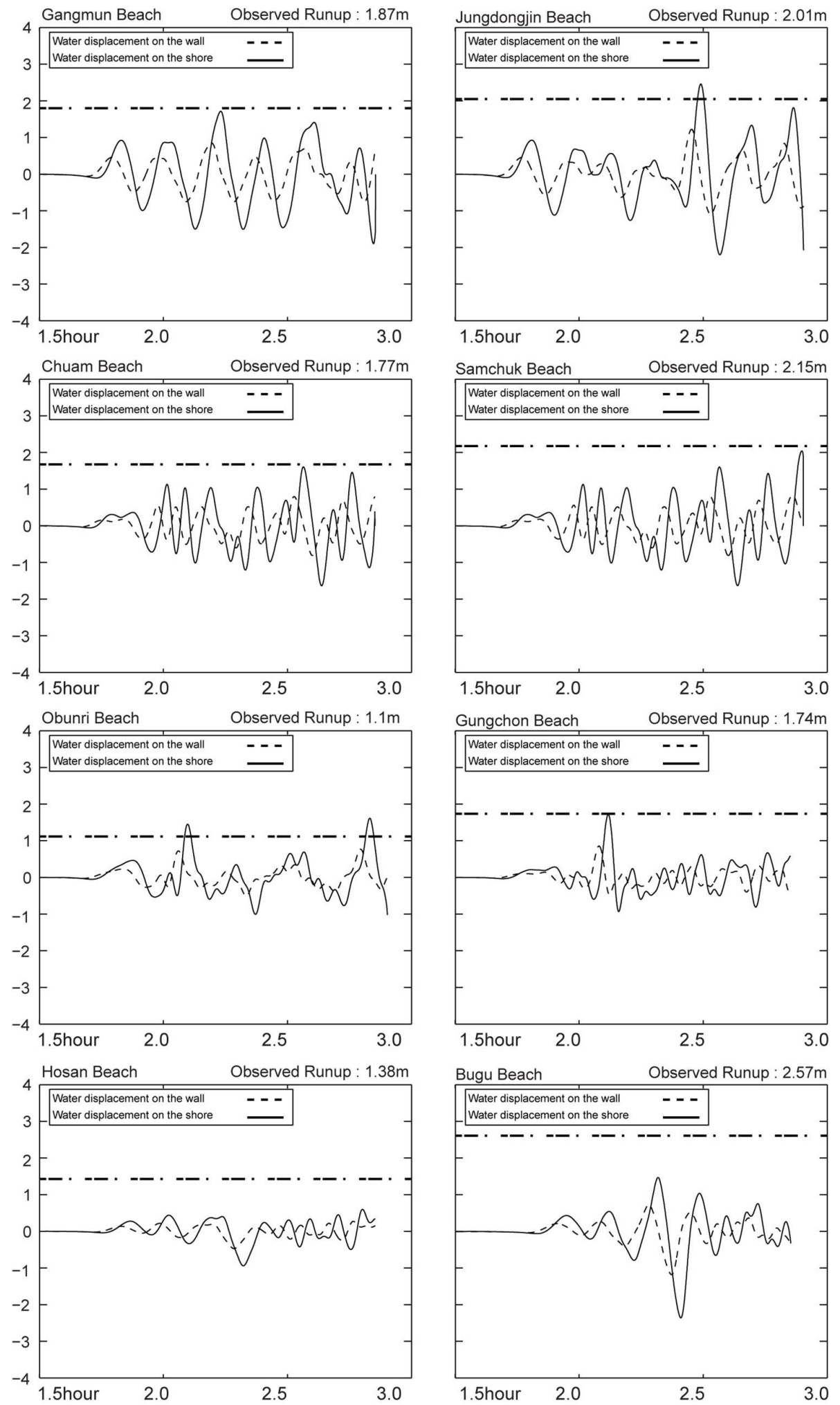

Fig. 5. Computed time series of water displacement on the vertical wall (dashed line) and on shore (solid line). The observed runup heights are shown by a dashed-dotted line. 
Table 1. Fault parameters of the 1993 Hokkaido earthquake.

\begin{tabular}{lllllllll}
\hline $\mathrm{N}\left({ }^{\circ} \mathrm{N}\right)$ & $\mathrm{E}\left({ }^{\circ} \mathrm{E}\right)$ & $\mathrm{h}_{f}(\mathrm{~km})$ & $\theta\left({ }^{\circ}\right)$ & $\delta\left({ }^{\circ}\right)$ & $\lambda\left({ }^{\circ}\right)$ & $\mathrm{L}(\mathrm{km})$ & $\mathrm{W}(\mathrm{km})$ & $\mathrm{U}(\mathrm{m})$ \\
\hline 42.10 & 139.30 & 5 & 163 & 60 & 105 & 24.5 & 25 & 12.00 \\
42.34 & 139.25 & 5 & 175 & 60 & 105 & 30 & 25 & 2.50 \\
43.13 & 139.40 & 10 & 188 & 35 & 80 & 90 & 25 & 5.71 \\
\hline
\end{tabular}

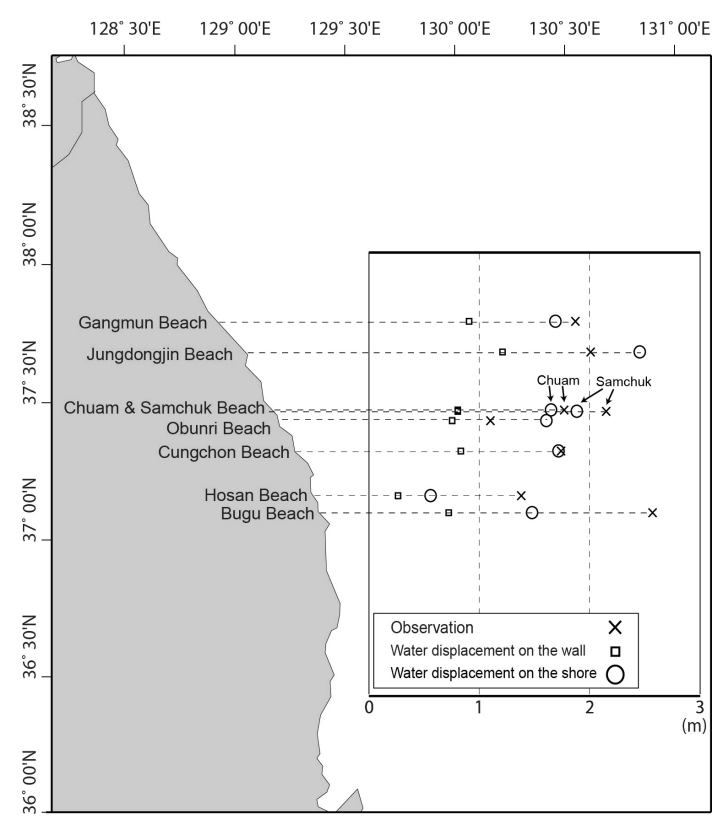

Fig. 6. Comparison of the computed and observed runup heights on the eastern Korean coast.

The Hokkaido-Nansei-Oki earthquake occurred at 13:17 UTC on 12 July 1993 . The epicentre of this earthquake was in the East (Japan) Sea at $42.8^{\circ} \mathrm{N}, 139.2^{\circ} \mathrm{E}$, about $15-30 \mathrm{~km}$ off the small offshore island of Okushiri along the west coast of Hokkaido (Fig. 3). The magnitude of the earthquake was 7.8. Over 230 people were killed, and a majority of deaths were caused by the tsunami. Property losses were approximately $\$ 600$ million. For the 1993 Hokkaido tsunami, the fault parameters suggested by Takahashi et al. (1994) are in Table 1 . Here $L$ is fault length, $W$ is fault width, $U$ is dislocation, $h_{f}$ is focal depth, $\theta$ is strike angle, $\delta$ is dip angle and $\lambda$ is slip angle. The initial surface profile at the source was determined by the method of Manshinha and Smylie (1971).

The boundary conditions near the coast are "no-flux": the normal component of the particle velocity or flow discharge to the boundary is zero, corresponding to a vertical wall at the last sea points.

We previously used this numerical shallow-water model in our earlier studies of tsunami waves in the East (Japan) Sea (Choi et al., 2002a, 2003).

Figure 4 shows the distribution of the maximum water elevations in the East Sea for the 1993 tsunami and the general direction of the tsunami's propagation. We can infer that the direction of the tsunami wave's propagation was slightly affected by bathymetry, because the general direction of propagation was to the north and to the Russian coasts. This movement focused the tsunami's energy away from the eastern edge of the East (Japan) Sea and the mid-eastern coast of Korea.

\section{The distribution of tsunami runup heights along the eastern Korean coast}

The tsunami that occurred on 12 July 1993 was well documented along the eastern Korean coast (Choi et al., 1994; Choi et al., 2002a). These observations were used to check the accuracy of the combined model. Figure 5 displays the time series of the water displacement along the vertical wall as computed by the finite-difference model (dashed line).The displacement of the water on the shore (solid line) was calculated using the integral in Eq. (14) for the coastal locations shown in Fig. 6. The amplification factor of the tsunami waves nearshore is approximately 2 to 2.2 . The observed maximal runup heights in these locations are given by numbers and by dash-point lines. The computations and observations agree well at all except two (the Hosan and Bugu Beaches) of the eight coastal locations.

\section{Conclusions}

Combining 2-D numerical models and 1-D analytical runup theory, we proposed a novel and rapid method for forecasting tsunami runups on the coasts. In the first step, the 2-D numerical simulations of tsunami generation and propagation are performed assuming impermeable boundary conditions of a 5-10 $\mathrm{m}$ depth at the last sea points (equivalent to a wall). Then the time series of the water oscillations on the wall are used to calculate the runup heights using the analytical integral expression following from 1-D theory. The accuracy of this approach was validated against the historic tsunami event in the East (Japan) Sea; the observed runup heights are in close agreement with the predicted values. We have demonstrated that the proposed approach is a more reasonable and rapid method of forecasting than complicated coastal inundation models. This new method can also be applied to other regions. 
Acknowledgements. We gratefully acknowledge support from the Korean National Emergency Management Agency. VK had particular support from RFBR (11-05-01054) and EP - from RFBR (11-05-00216) and Russian State Contract No. 02.740.11.0732. The third author was supported by the Korea Ocean Research \& Development Institute (PE98533). The authors thank Carl Harbitz, Ira Didenkulova and two anonymous reviewers for very useful comments.

Edited by: I. Didenkulova

Reviewed by: C. B. Harbitz, D. Greenslade, and another anonymous referee

\section{References}

Abramowitz, M. and Stegun, I. A.: Handbook of mathematical functions with formulas, graphs and mathematical tables, National Bureau of Standards, NY, 1046 pp., 1964.

Antuono, M. and Brocchini, M.: The boundary value problem for the nonlinear shallow water equation, Studied Applied Mathematics, 119, 71-91, 2007.

Antuono, M. and Brocchini, M.: Maximum run-up, breaking conditions and dynamical forces in the swash zone: a boundary value approach, Coastal Eng., 55, 732-740, 2008.

Antuono, M. and Brocchini, M.: Solving the nonlinear shallowwater equations in physical space, J. Fluid Mech., 643, 207-232, 2010.

Beisel, S., Chubarov, L., Didenkulova, I., Kit, E., Levin, A., Pelinovsky, E., Shokin, Y., and Sladkevich M.: The 1956 Greek tsunami recorded at Yafo (Israel) and its numerical modeling. J. Geophys. Res., 114, C09002, doi:10.1029/2008JC005262, 2009.

Briganti, R. and Dodd, N.: Shoreline motion in nonlinear shallow water coastal models, Coastal Eng., 56, 495-505, 2009.

Carrier, G. F. and Greenspan, H. P.: Water waves of finite amplitude on a sloping beach, J. Fluid Mech., 4, 97-109, 1958.

Carrier, G. F., Wu, T. T., and Yeh, H.: Tsunami run-up and drawdown on a plane beach, J. Fluid Mech., 475, 79-99, 2003.

Choi, B. H., Ko, J. S., Chung, H. F., Kim, E. B., Oh, I. S., Choi, J. I., Sim, J. S., and Pelinovsky, E.: Tsunami runup survey at East Coast of Korea due to the 1993 Southwest of the Hokkaido Earthquake, J. Korean Soc. Coastal and Ocean Engineers, 6, 117-125, 1994 (in Korean).

Choi, B. H., Pelinovsky, E., Riabov, I., and Hong, S. J.: Distribution functions of tsunami wave heights, Natural Hazards, 25, 1-21, 2002a.

Choi, B. H., Kim, K. O., and Eum, H. M.: Digital bathymetric and topographic data for neighboring seas of Korea. J. Korean Soc. Coastal and Ocean Eng., 14, 41-50, 2002b (in Korean with English abstract and figure captions).

Choi, B. H., Pelinovsky, E., Hong, S. J., and Woo, S. B.: Computation of tsunami in the East (Japan) Sea using dynamically interfaced nested model, Pure Applied Geophys., 160, 1383-1414, 2003.

Dall'Osso, F., Maramai, A., Graziani, L., Brizuela, B., Cavalletti, A., Gonella, M., and Tinti, S.: Applying and validating the PTVA-3 Model at the Aeolian Islands, Italy: assessment of the vulnerability of buildings to tsunamis, Nat. Hazards Earth Syst. Sci., 10, 1547-1562, doi:10.5194/nhess-10-1547-2010, 2010.
Didenkulova, I.: New trends in the analytical theory of long sea wave runup, in: Applied Wave Mathematics: Selected Topics in Solids, Fluids, and Mathematical Methods, edited by: Quak, E. and Soomere, T. , Springer, 265-296, 2009.

Didenkulova, I. and Pelinovsky, E.: Run-up of long waves on a beach: the influence of the incident wave form, Oceanology, 48, 1-6, 2008.

Didenkulova, I. and Pelinovsky, E.: Traveling water waves along quartic bottom profile, Proc. Estonian Acad. Sciences, 59, 166$171,2010$.

Didenkulova, I., Zahibo, N., Kurkin, A., Levin, B., Pelinovsky, E., and Soomere T.: Runup of nonlinear deformed waves on a beach, Doklady Earth Sciences, 411(8), 1241-1243, 2006.

Didenkulova, I., Pelinovsky, E., and Soomere, T.: Run-up characteristics of tsunami waves of "unknown" shapes, Pure Appl. Geophys., 165, 2249-2264, 2008.

Didenkulova, I., Pelinovsky, E., and Soomere, T.: Long surface wave dynamics along a convex bottom, J. Geophys. Res.Oceans, 114, C07006, doi:10.1029/2008JC005027, 2009.

Dobrokhotov, S. Yu. and Tirozzi, B.: Localized solutions of onedimensional non-linear shallow-water equations with velocity $\mathrm{c}$ $=(\mathrm{x})^{1 / 2}$, Uspekhi Math Nauk, 65, 77-180, 2010.

Dominey-Howes, D. and Papathoma, M.: Validating a tsunami vulnerability assessment model (the PTVA Model) using field data from the 2004 Indian Ocean tsunami, Natural Hazards, 40, 113 136, 2007.

Gayer, G., Leschka, S., Nöhren, I., Larsen, O., and Günther, H.: Tsunami inundation modelling based on detailed roughness maps of densely populated areas, Nat. Hazards Earth Syst. Sci., 10, 1679-1687, doi:10.5194/nhess-10-1679-2010, 2010.

Glimsdal, S., Pedersen, G. K., Atakan. K., Harbitz, C. B., Langtangen, H. P., and Løvholt, F.: Propagation of the Dec. 262004 Indian Ocean Tsunami: effects of dispersion and source characteristics, Int. J. Fluid Mech. Res., 33, 15-43, 2006.

Gonzalez, F., Geist, E. L., Jaffe, B., Kanoglu, U., Mofjeld, H., Synolakis, C. E., Titov, V. V., Arcas, D., Bellomo, D., Carlton, D., Horning, T., Johnson, J., Newman, J., Parsons, T., Peters, R., Peterson, C., Priest, G., Venturato, A., Weber, J., Wong, F., and Yalciner, A.: Probabilistic tsunami hazard assessment at Seaside, Oregon, for near- and far-field seismic sources, J. Geophys. Res., 114, C11023, doi:10.1029/2008JC005132, 2009.

Harbitz, C. and Pedersen, G.: Model theory and analytical solutions for large water waves due to landslides, Tech. Rep. 4, Preprint Series Dept of Mathematics, University of Oslo, 17 pp., 1992.

Ioualalen, M., Pelinovsky, E., Asavanant, J., Lipikorn, R., and Deschamps, A.: On the weak impact of the 26 December Indian Ocean tsunami on the Bangladesh coast, Nat. Hazards Earth Syst. Sci., 7, 141-147, doi:10.5194/nhess-7-141-2007, 2007.

Kaistrenko, V., Go, C. N., and Chung, J. Y.: A simple method for tsunami wave form recalculation through the shelf, IOC-IUGG Joint International Workshop on Tsunami Warning Beyond 2000 Theory, Practice and Plans, Korea, Seoul, 15 p., 1999.

Kaistrenko, V. M., Mazova, R. Kh., Pelinovsky, E. N., and Simonov, K. V.: Analytical theory for tsunami run up on a smooth slope, Sci. Tsunami Hazards, 9, 115-127, 1991.

Kânoğlu, U.: Nonlinear evolution and run-up-rundown of long waves over a sloping beach, J. Fluid Mech., 513, 363-372, 2004.

Kânoğlu, U. and Synolakis, C. E.: Long wave runup on piecewise linear topographies, J. Fluid Mech., 374, 1-28, 1998. 
Kânoğlu, U. and Synolakis, C.: Initial value problem solution of nonlinear shallow water-wave equations, Phys. Rev. Lett., 97, 148501, 2006.

Løvholt, F., Bungum, H., Harbitz, C. B., Glimsdal, S., Lindholm, C. D., and Pedersen, G.: Earthquake related tsunami hazard along the western coast of Thailand, Nat. Hazards Earth Syst. Sci., 6, 979-997, doi:10.5194/nhess-6-979-2006, 2006.

Madsen, P. A. and Fuhrman, D. R.: Run-up of tsunamis and long waves in terms of surf-similarity, Coastal Eng., 55, 209-223, 2008.

Manshinha, L. and Smylie, D. E.: The displacement fileds of inclined faults. Bulletin of the Seismological Society of America, 61, 1433-1440, 1971.

Pedersen, G. and Gjevik, B.: Run-up of solitary waves, J. Fluid Mech., 142, 283-299, 1983.

Pelinovsky, E. and Mazova, R.: Exact analytical solutions of nonlinear problems of tsunami wave run-up on slopes with different profiles, Natural Hazards, 3, 227-249, 1992.

Roger, J. and Hébert, H.: The 1856 Djijelli (Algeria) earthquake and tsunami: source parameters and implications for tsunami hazard in the Balearic Islands, Nat. Hazards Earth Syst. Sci., 8, 721-731, doi:10.5194/nhess-8-721-2008, 2008.

Roger, J., Allgeyer, S., Hebert, H., Baptista, M.A., Loevenbruck, A., and Schindele, F.: The 1755 Lisbon tsunami in Guadeloupe Archipelago: source sensitivity and investigation of resonance effects, Open Oceanography Journal, 4, 58-70, 2010.

Sato, H., Murakami, H., Kozuki, Y., and Yamamoto. N.: Study on a simplified method of tsunami risk assessment, Natural Hazards, 29, 325-340, 2003.

Schuiling, R. D., Cathcart, R. B., Badescu, V., Isvoranu, D., and Pelinovsky, E.: Asteroid impact in the Black Sea. Death by drowning or asphyxiation?, Natural Hazards, 40, 327-338, 2007.

Shuto, N.: Standing Waves in Front of a Sloping. Dike, Coastal Engineering in Japan, JSCE, 15, 13-23, 1972.

Synolakis, C. E.: The run-up of solitary waves. J. Fluid Mech., 185, 523-545, 1987.
Synolakis, C. E.: Tsunami run-up on steep slopes: How good linear theory really is?, Natural Hazards, 4, 221-234, 1991.

Tadepalli, S. and Synolakis, C. E.: The run-up of N-waves, P. R. Soc. London, A445, 99-112, 1994.

Takahashi, T., Shuto, N., Imamura, F., and Ortiz, M.: The best fault model for the 1993 Hokkaido Nansei-Oki earthquake tsunami, Proc. Coastal Eng., 41, 251-255 , 1994 (in Japanese).

Tinti, S. and Tonini, R.: Analytical evolution of tsunamis induced by near-shore earthquakes on a constant-slope ocean, J. Fluid Mech., 535, 33-64, 2005.

Titov, V. V. and Synolakis, C. E.: Modeling of breaking and nonbreaking long-wave evolution and runup using VTCS-2., J. Waterw. Port. C-Asce, 121, 308-316, 1995.

Titov, V. V. and Synolakis, C. E.: Numerical modeling of tidal wave runup, J. Waterw. Port. C-Asce, 124, 157-171, 1998.

Titov, V. V., Moore, C., Greenslade, D. J. M., Pattiaratchi, C., Badal, R., Synolakis, C. E., and Kanoglu, U.: A new tool for inundation mapping: Community Modeling Interface for Tsunamis (ComMIT), Pure Appl. Geophys., Topical Volume, Accepted Dec. 2010, 2011.

Ward, S. N. and Asphaug, E.: Asteroid impact tsunami of 2880 March 16, Geophys. J. Int., 153, F6-F10, 2003.

Wei, Y., Bernard, E., Tang, L., Weiss, R., Titov, V., Moore, C., Spillane, M., Hopkins, M., and Kânoğlu, U.: Realtime experimental forecast of the Peruvian tsunami of August 2007 for U.S. Coastlines, Geophys. Res. Lett., 35, L04609, doi:10.1029/2007GL032250, 2008.

Zaitsev, A. I., Kovalev, D. P., Kurkin, A. A., Levin, B. V., Pelinovskii, E. N., Chernov, A. G., and Yalciner, A.: The tsunami on Sakhalin on August 2, 2007: Mareograph evidence and numerical simulation, Russian J. Pacific Geology, 3, 437-442, 2009. 